\title{
BMJ Open Gravidity, parity, blood pressure and mortality among women in Bangladesh from the HEALS cohort
}

\author{
Yu-Hsuan Shih (D) , ${ }^{1}$ Molly Scannell Bryan, ${ }^{2}$ Faruque Parvez, ${ }^{3}$ \\ Keriann Hunter Uesugi, ${ }^{1}$ Mohammed Shahriar, ${ }^{4}$ Alauddin Ahmed, ${ }^{4}$ Tariqul Islam, ${ }^{4}$ \\ Habibul Ahsan, ${ }^{5}$ Maria Argos ${ }^{1}$
}

To cite: Shih Y-H, Scannell Bryan M, Parvez F, et al. Gravidity, parity, blood pressure and mortality among women in Bangladesh from the HEALS cohort. BMJ Open 2020;10:e037244. doi:10.1136/ bmjopen-2020-037244

- Prepublication history and additional material for this paper are available online. To view these files, please visit the journal online (http://dx.doi. org/10.1136/bmjopen-2020037244).

Received 24 January 2020 Revised 11 June 2020 Accepted 17 July 2020

\section{Check for updates}

(C) Author(s) (or their employer(s)) 2020. Re-use permitted under CC BY-NC. No commercial re-use. See rights and permissions. Published by BMJ.

${ }^{1}$ Division of Epidemiology and Biostatistics, School of Public Health, University of Illinois at Chicago, Chicago, Illinois, USA ${ }^{2}$ Institute for Minority Health Research, College of Medicine, University of Illinois at Chicago, Chicago, Illinois, USA

${ }^{3}$ Department of Environmental Health Sciences, Columbia University Mailman School of Public Health, New York, New York, USA

${ }^{4}$ UChicago Research

Bangladesh, Dhaka, Bangladesh ${ }^{5}$ Department of Public Health Sciences, University of Chicago, Chicago, Illinois, USA

Correspondence to

Dr Maria Argos; argos@uic.edu

\section{ABSTRACT}

Objectives Despite a hypothesised connection of reproductive history with hypertension and mortality, the nature of this association is poorly characterised. We evaluated the association of parity and gravidity with blood pressure, hypertension and all-cause mortality.

Design Prospective cohort study.

Setting Health Effects of Arsenic Longitudinal Study cohort in rural Bangladesh.

Participants There were 21634 Bangladeshi women recruited in 2000-2002, 2006-2008 and 2010-2014 included in the present analysis.

Methods Reproductive history was ascertained through an interviewer-administered questionnaire at the baseline visit. Blood pressure was measured by a trained study physician following a standard protocol at the baseline visit. Vital status was ascertained at the biennial followup of study participants through June 2017. Linear and logistic regression models estimated the relationship between parity and gravidity with blood pressure and hypertension, respectively. Cox proportional hazards models estimated the relationship with all-cause mortality only among women aged $>45$ years.

Results Diastolic blood pressure was lowest in women with parity one (reference) and elevated in nulliparous women (adjusted \% change $=3.12 ; 95 \% \mathrm{Cl} 1.93$ to 4.33 ) and women with parity $\geq 2$ (adjusted $\%$ change $=1.71$; $95 \% \mathrm{Cl} 1.12$ to 2.31 ). The associations with nulliparity were stronger for women aged $>45$ years. Similar association patterns were observed with hypertension. Further, in nulliparous women aged $>45$ years, 265 deaths $(6.6 \%)$ were ascertained during the follow-up period (median follow-up time $=8$ years), and we observed suggestive elevated risks of all-cause mortality (adjusted HR 3.83; $95 \% \mathrm{Cl} 0.74$ to 19.78). The relationships between reproductive history, blood pressure, hypertension and mortality were similar when modelling reproductive history as gravidity rather than parity.

Conclusions For women in rural Bangladesh, nulliparity and nulligravidity appear to be associated with higher blood pressure and subsequent elevated risk of mortality.

\section{INTRODUCTION}

Elevated blood pressure is an established risk factor for cardiovascular diseases (CVDs), ${ }^{12}$ and complications of hypertension account
Strengths and limitations of this study

- Large, rigorously conducted prospective study in a middle-income country context.

- Childbearing history was self-reported, and menopause status was not ascertained.

- Unmeasured confounders may remain unaccounted for in our analyses.

for approximately 9.4 million deaths worldwide. ${ }^{3}$ In Bangladesh, as in other South Asian countries, hypertension is a significant health concern with an overall prevalence of $26.4 \%$ among adults, with a higher prevalence $(32.4 \%)$ in women. ${ }^{4}$

A woman's risk for developing hypertension is influenced by several factors, including age, body mass index (BMI), menopause, dietary behaviour and physical activity. ${ }^{4} 5$ Previous research has also provided suggestive evidence that pregnancy and childbirth influence blood pressure and subsequent morbidity and mortality. Pregnancy and childbirth may affect long-term cardiovascular health by several mechanisms, some of which are thought to be protective (elevated oestrogen levels during the pregnancy ${ }^{6}$ ), and others of which are thought to increase risk (functional vascular property changes, decreased lipid and glucose metabolism, oxidative stress ${ }^{8-11}$ and haemodynamic changes during the pregnancy ${ }^{12}$ ). Further complicating the evaluation of this relationship is the possibility that a subset of nulliparous and nulligravid women did not conceive because of an underlying health issue, which may be an independent risk factor for CVD, such as polycystic ovary syndrome and uterine leiomyoma. $^{1314}$

Studies, largely in populations of European descent, have investigated the association between reproductive history and blood pressure. $^{12}{ }^{15-21}$ Still, the findings have been 
equivocal and have not adequately addressed the effect of nulliparity and nulligravidity. Studies investigating parity and mortality have also been inconsistent, and these studies have differed in study design, sample size or confounders for which a study adjusted. ${ }^{22-27}$ Two large meta-analyses of cohort studies ${ }^{26}{ }^{27}$ largely without South Asian participants, suggest J-shaped associations, with parities of 1-6 negatively related to all-cause and CVD mortality, and nulliparous women at increased risk. Only one study, using data collected from 1982 to 1998, has examined the effect of parity on all-cause mortality among Bangladeshi women aged 45-55 years and observed no association. ${ }^{28}$

Given the multiple pathways that may connect reproductive history to morbidity and mortality, it remains unclear whether any associations found in other populations are also valid for the Bangladeshi context as well as other middle-income countries. Therefore, this study aimed to evaluate the associations of parity and gravidity with blood pressure and mortality in Bangladeshi women.

\section{METHODS}

\section{Study population}

The Health Effects of Arsenic Longitudinal Study (HEALS) is an ongoing population-based study in Araihazar, Bangladesh. To establish the cohort, a sampling frame was developed based on demographic, geographical and well water arsenic data collected through a complete enumeration of the geographically defined $25 \mathrm{~km}^{2}$ study area through a house-to-house survey, as has been detailed elsewhere. ${ }^{29}$ Between October 2000 and May 2002, we recruited 11746 participants (5042 males and 6704 females) who met the following eligibility criteria: (1) married couples/individuals (to reduce lost to follow-up); (2) aged 18-75 years; (3) users of a tube well as a primary water supply; and (4) residents of the study area for at least 5 years. During 2006-2008 (ACE I) and 2010-2014 (ACE II), the cohort was expanded to include an additional 8287 (3121 males and 5166 females) and 15 018 participants (5039 males and 9979 females), respectively, using rosters established based on well water arsenic measurements in the same study area following the same recruitment methods. The overall response rate among those approached for participation was $97.5 \%$. Study participants underwent clinical assessment and face-toface structured interviews to ascertain demographic and lifestyle characteristics. Enrolled participants were subsequently visited biennially for follow-up evaluation at their home, including face-to-face interviewer-administered interviews and clinical assessment. More detailed information, including study design and data collection, can be found elsewhere. ${ }^{29}$ Verbal consent, in the presence of a witness, was obtained from each eligible respondent who agreed to participate in the study; verbal consent was obtained to facilitate participation among individuals with low literacy. In the present study, we restricted our analyses to the 21634 women (99\%) with no missing data on exposures, outcomes and covariates of interest.

\section{Assessing parity and gravidity}

The primary exposure variables are the number of total births (parity) and the number of pregnancies (gravidity). Gravidity, number of livebirths, number of stillbirths and number of abortions were obtained from the intervieweradministered baseline questionnaire. Parity was derived by subtracting the number of abortions from the total number of pregnancies.

\section{Assessing blood pressure}

Blood pressure was measured by a trained study physician using an automated sphygmomanometer with a digital display at the baseline visit. ${ }^{30}$ Subjects remained seated for $5 \mathrm{~min}$, and blood pressures were taken with the cuff around their upper left arms. After 5 min of rest, a second reading was taken and averaged with the first. Participants were asked by trained interviewers to list any medications they were currently taking, and $2.4 \% \quad(n=523)$ reported taking antihypertensive medication. For those participants, 10 and $5 \mathrm{~mm} \mathrm{Hg}$ were added to their observed systolic and diastolic blood pressures, respectively, to account for the magnitude of the potential treatment effect. $^{31}{ }^{32}$ In subsequent analyses, blood pressure was modelled as a natural log-transformed continuous variable to improve normality. Hypertension was also defined based on the Joint National Committee (JNC) 8 guideline as systolic blood pressure $\geq 140 \mathrm{~mm} \mathrm{Hg}$ or diastolic blood pressure $\geq 90 \mathrm{~mm} \mathrm{Hg}^{33}$

\section{Assessing mortality}

The vital status of each participant was ascertained at biennial follow-up visits through June 2017. Follow-up time was calculated as the number of days between the baseline visit and date of death or, if alive, the date of the last report of being alive.

A verbal autopsy (VA) procedure, previously validated by the International Centre for Diarrhoeal Disease Research, Bangladesh, was implemented to investigate and assign the cause of death for the study participants in the HEALS cohort. In brief, an in-person interview with the informant (relative or neighbour) of the deceased participant was conducted by a trained study physician to complete the VA questionnaire. If the death occurred in the hospital, supplemental documents regarding disease condition prior to death from the hospital, treating physician or death certificate were obtained. A panel of expert physicians assigned a single cause of death. We coded the assigned cause of death based on the WHO's 10th revision of the International Classification of Disease (ICD10). ${ }^{34}$ Deaths classified with ICD-10 codes I00-I99 were attributed to CVD.

\section{Assessing covariates}

Self-reported participant characteristics including age, years of education, occupation (daily labourer/farmer, factory worker, business, homemaker, other), smoking 
status (current, former, never) and land ownership (yes, no) were derived from the baseline intervieweradministered questionnaire. BMI was calculated as measured weight in kilograms divided by measured height in metres squared; a trained study physician measured both during the baseline interview following a standard protocol.

\section{Statistical analysis}

We assessed associations between participant characteristics and parity using analysis of variance for continuous variables and Pearson $\mathrm{X}^{2}$ tests for dichotomous variables. Since qualitative examination of the data (figure 1) revealed no variation in the observed effects for parity and gravidity of two, three, four or more, parity and gravidity were subsequently analysed as three category variables: 0 , 1 and $\geq 2$.

\section{Blood pressure and hypertension}

Linear regression models were used to estimate the percent changes and 95\% CIs in both systolic and diastolic blood pressures. The percent change was calculated as $\left(\mathrm{e}^{\beta}-1\right) \times 100 \%$, with $95 \%$ CIs calculated as $\left(\mathrm{e}^{(\beta \pm 1.96 \times \mathrm{SE})}\right.$ $-1) \times 100 \%$. Logistic regression models were used to estimate ORs and their CIs for the associations of the dichotomous hypertension variable with parity and gravidity. Three models were fit: (1) adjusted for cohort (HEALS, ACE I, ACE II); (2) adjusted for cohort and age (years); and (3) adjusted for cohort, age, years of education
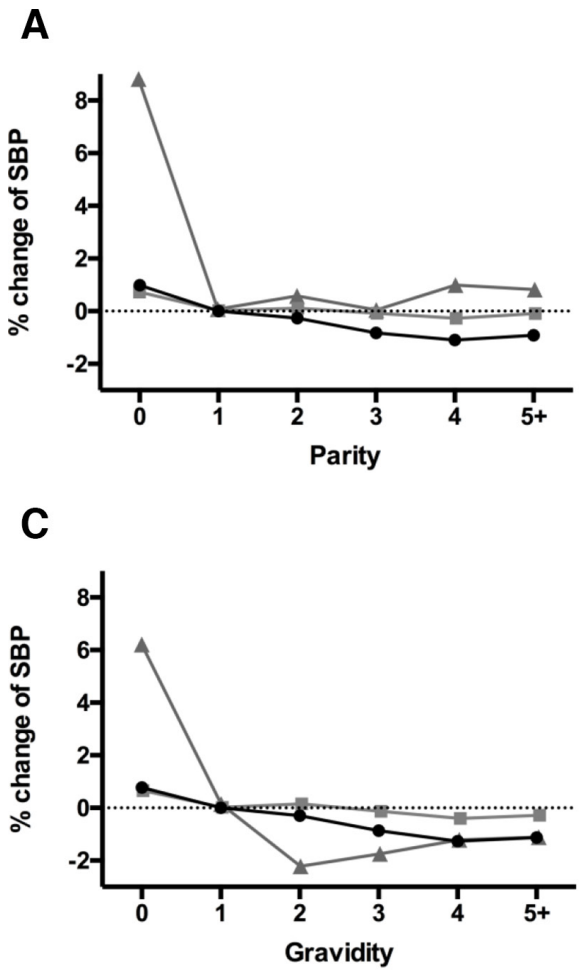

(years), formal education (yes, no), land ownership (yes, no), smoking status (current, former, never) and BMI $\left(\mathrm{kg} / \mathrm{m}^{2}\right)$. Since menopause is an important risk factor for elevated blood pressure ${ }^{35} 36$ the blood pressure analyses were repeated separately for women aged $\leq 45$ years $(n=17$ $621)$ and women aged $>45$ years $(n=4013)$ since menopause status was not available. Arsenic was not included in the analyses since no confounding effect was observed.

\section{Mortality}

Cox proportional hazard models were used to estimate HRs and 95\% CIs for the association of parity and gravidity with all-cause mortality and CVD mortality among 4013 women aged $>45$ years. Two models were fit: (1) adjusted for cohort and age; and (2) further adjusted including cohort, age, years of education, formal education, land ownership, smoking status and BMI $\left(\mathrm{kg} / \mathrm{m}^{2}\right)$, and number of abortions.

\section{Sensitivity analyses}

Two sensitivity analyses were conducted to test the robustness of the analyses. The first sensitivity analysis restricted to 11662 women (54\%) from the first two recruitment cycles with available information on hormonal contraceptive use since hormonal contraceptive use may also confound the relationship between reproductive history and cardiovascular health. ${ }^{37}$ Of 11662 women, 26\% (n=3 018) had used hormonal contraceptives. On this subset, the adjusted model was rerun for the blood pressure and
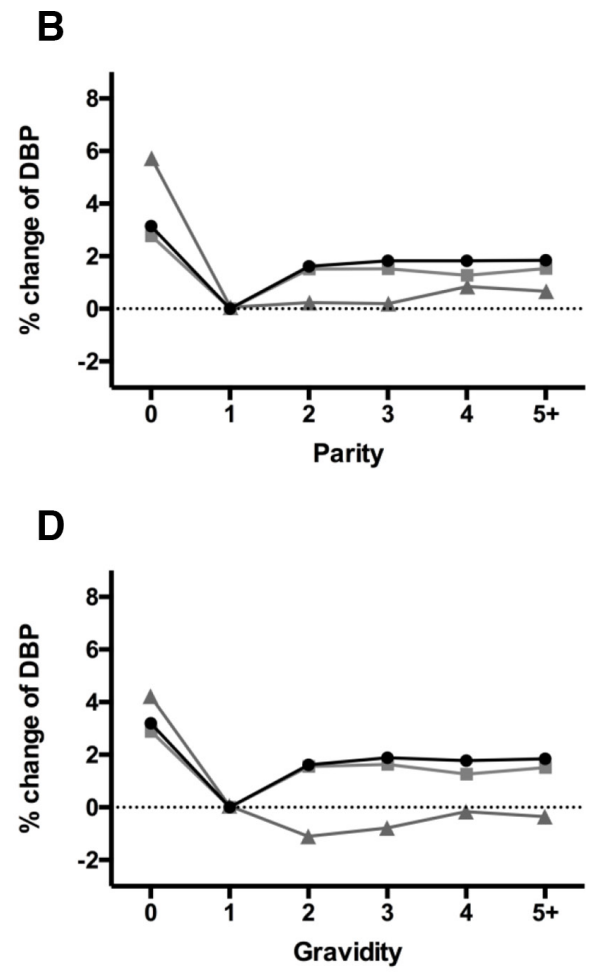

$\rightarrow$ Overall $\rightarrow$ Age $\leq 45$ years $\rightarrow$ Age $>45$ years

Figure 1 Adjusted percent change for the association between reproductive history and blood pressure, overall and stratified on 45years of age: (A) parity and systolic blood pressure (SBP); (B) parity and diastolic blood pressure (DBP). 
hypertension outcomes, including current hormonal contraceptive use as an additional covariate. In the second sensitivity analysis, we defined hypertension based on the 2019 American College of Cardiology and American Heart Association (ACC/AHA) Guideline as systolic blood pressure $\geq 130 \mathrm{~mm} \mathrm{Hg}$ or diastolic blood pressure $\geq 80 \mathrm{~mm} \mathrm{Hg} .{ }^{38}$

\section{Patient and public involvement}

There was no patient or public involvement in the design, conduct, reporting, or dissemination plans of our research.

\section{RESULTS}

Table 1 shows the characteristics of all 21634 women, overall and by parity. Since gravidity correlated with parity in the present study $(\mathrm{r}=0.98)$, participant characteristics in relation to gravidity are not shown in table 1. The average number of total births was $3.8(\mathrm{SD}=2.4)$, with a range of $0-15$ births and a mode of 2. A total of 605 $(2.8 \%)$ women were nulliparous. The means of systolic and diastolic blood pressure were 114.4 and $75.0 \mathrm{~mm}$
$\mathrm{Hg}$, respectively, and the prevalence of hypertension was $5.7 \%$. The mean age of the study participants was 34.9 years (range: 18-65 years). Almost all women in the study were never-smokers. In parous women, increased age, no formal education, tobacco use and land ownership were associated with higher parity. Furthermore, parity was positively associated with systolic and diastolic blood pressures and the prevalence of hypertension.

\section{Association between blood pressure, hypertension, parity and} gravidity

Table 2 summarises the associations of parity with blood pressure. Compared with women with a parity of one, nulliparous women and women with a parity $\geq 2$ were more likely to have higher blood pressure in model 1 . The magnitude of the associations changed considerably after adjusting for age (model 2), suggesting age is an important confounder. The associations were further attenuated when we additionally adjusted for other confounders (model 3). Model 3 shows that, overall, women with a parity of one have the lowest blood pressure, and both nulliparous and parity $\geq 2$ associate with

Table 1 Selected characteristics of 21634 Bangladeshi women in the HEALS cohort

\begin{tabular}{|c|c|c|c|c|c|}
\hline \multirow[b]{2}{*}{ Characteristics } & \multirow{2}{*}{$\begin{array}{l}\text { All } \\
(n=21634)\end{array}$} & \multicolumn{3}{|l|}{ Total parity } & \multirow[b]{2}{*}{ P value* $^{*}$} \\
\hline & & $0(n=605)$ & $1(n=2731)$ & $2+(n=18298)$ & \\
\hline Systolic BP, mm Hg (mean (SD))† & $114.37(17.07)$ & $113.61(17.92)$ & $109.83(12.99)$ & $115.07(17.46)$ & $<0.0001$ \\
\hline Hypertension (n (\%)) & $1239(5.7)$ & $30(5.0)$ & $52(1.9)$ & 1157 (6.3) & $<0.0001$ \\
\hline Age, years (mean (SD)) & $34.87(10.67)$ & $28.46(9.69)$ & $24.73(6.39)$ & $36.59(10.28)$ & $<0.0001$ \\
\hline Yes & 12697 (58.7) & 429 (70.9) & $2323(85.1)$ & $9945(54.4)$ & \\
\hline No & 8937 (41.3) & $176(29.1)$ & $408(14.9)$ & $8353(45.7)$ & \\
\hline Land ownership (n (\%)) & & & & & 0.02 \\
\hline Yes & $10167(47.0)$ & $293(48.4)$ & $1214(44.5)$ & $8660(47.3)$ & \\
\hline No & $11467(53.0)$ & $312(51.2)$ & $1517(55.6)$ & $9638(52.7)$ & \\
\hline Factory worker & $741(3.4)$ & $15(2.5)$ & $82(3.0)$ & $644(3.5)$ & \\
\hline Business & $403(1.9)$ & $9(1.5)$ & $62(2.3)$ & $332(1.8)$ & \\
\hline Homemaker & $19845(91.7)$ & $553(91.4)$ & $2500(91.5)$ & 16792 (91.8) & \\
\hline Other & $599(2.7)$ & $27(4.4)$ & $84(3.0)$ & $488(2.7)$ & \\
\hline Smoking status (n (\%)) & & & & & $<0.0001$ \\
\hline Current & $486(2.3)$ & $11(1.8)$ & $17(0.6)$ & $458(2.5)$ & \\
\hline Former & $449(2.1)$ & $4(0.7)$ & $9(0.3)$ & $436(2.4)$ & \\
\hline Never & 20669 (95.7) & $590(97.5)$ & 2705 (99.05) & 17404 (95.1) & \\
\hline $\mathrm{BMI}, \mathrm{kg} / \mathrm{m}^{2}$ (mean (SD)) $\ddagger$ & $20.70(3.57)$ & $21.14(3.82)$ & $20.85(3.37)$ & $20.66(3.59)$ & 0.0004 \\
\hline
\end{tabular}

${ }^{*}$ Analysis of variance for continuous variable and Pearson chi-squared test for dichotomous variables.

†Blood pressure (BP).

$\ddagger$ Łody mass index. 


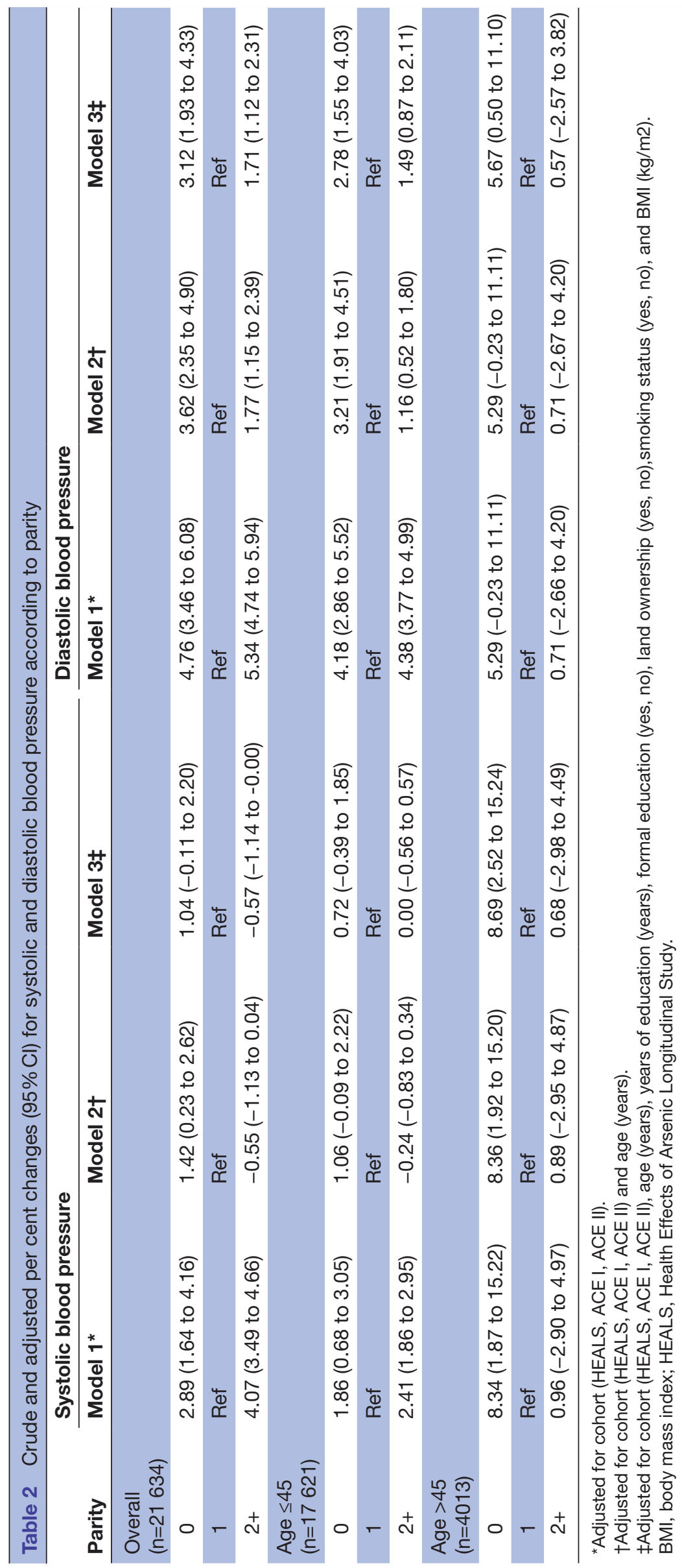


higher diastolic blood pressure. The CIs of the estimates for systolic blood pressure are consistent with the null, although the magnitude of the estimates suggests an increase in systolic pressure for nulliparous women. After stratifying at 45 years of age, the associations with nulliparity were attenuated for women aged $\leq 45$ years, while larger effect sizes were seen for women aged $>45$ years.

Table 3 summarises the associations of gravidity with blood pressure, which have similar patterns to those observed with parity. While no relationship between gravidity and systolic blood pressure was found, we observed positive associations of nulligravid and gravidity $\geq 2$ with diastolic blood pressure. As with the parity analysis, we observed stronger relationships for women aged $>45$ years, where nulligravidity was associated with higher systolic and diastolic pressures.

Table 4 presents the associations of parity and gravidity with hypertension. In model 3, nulliparous women had a higher risk of having hypertension compared with women with a parity of one. As with the analyses in relation to blood pressure, larger effect estimates were observed for women aged $>45$ years, although the CIs contained the null. No significant associations were observed in relation to gravidity.

\section{Association between mortality, parity and gravidity}

We observed 265 deaths (6.6\%) among 4013 women aged $>45$ years during the study period (median follow-up time $=8$ years $($ range 5 days to 16.7 years $)$ ). Of this, 101 women $(38.1 \%)$ died of CVD-related causes, and no women died of childbirth-related conditions. Since the number of deaths was not sufficient to conduct analysis in relation to CVD mortality, online supplementary table 1 shows the associations of parity and gravidity with allcause mortality. Although the CIs were wide, and they included the null, elevated risks of all-cause mortality were observed for nulliparity and nulligravidity.

\section{Sensitivity analyses}

A sensitivity analysis was conducted to account for the potential confounding effect of hormonal contraceptive use restricted to the 11662 women $(54 \%)$ with available data. After additionally adjusting for contraceptive use, the associations of gravidity and parity with blood pressure became stronger, suggesting a negative confounding effect (online supplementary table 2). A similar phenomenon was observed in relation to hypertension (data are not shown). Additionally, we performed the analysis in relation to hypertension using the 2019 ACC/AHA Guideline to define hypertensive women. As shown in online supplementary table 3 , associations observed using this hypertension definition were stronger as compared with the original hypertension variable defined by the JNC 8 guideline.

\section{DISCUSSION}

This analysis finds that in a population of women in rural Bangladesh, nulliparous women and women with a parity $\geq 2$ have increased blood pressure, but only nulliparous women were observed to have a higher risk of hypertension. The associations with nulliparity were stronger in women $>45$ years old. Furthermore, there was suggestive evidence of higher subsequent mortality among nulliparous women aged $>45$ years old. This study contributes valuable information to the current evidence on the impacts of reproductive history on the risk of CVD in a low- and middle-income country context.

The proportion of women in our study who actively decided not to have children is unclear, but given the relatively high birth rate in Bangladesh, the proportion of women who are nulliparous or nulligravid due to underlying issues causing infertility may be larger than the proportion of such women in studies from countries with lower birth rates. This may explain why our results suggest a larger risk for nulliparous and nulligravid women than seen in some previous studies.

The associations between reproductive history, blood pressure and hypertension found in our study are consistent with findings from three large studies based in the USA, Korea and Norway. ${ }^{12} 1521$ However, all of these studies are in contrast to other studies conducted in US populations, which suggested no association ${ }^{16}$ or a higher risk of hypertension with each additional birth. ${ }^{18} 19$ The discrepancies may be due to modelling differences, as these studies compared grand parity ( $\geq 5$ births) to lowto-moderate parity without including nulliparous women in the analyses.

Our analysis of parity may help clarify previous contradictory results on mortality. Using data collected from 1982 to 1998 , a study among Bangladeshi women aged 45-55 years observed no association between parity and all-cause mortality. ${ }^{28}$ Another study of 518 Amish women with a mean age of 63.1 years also reported no association between parity and mortality. ${ }^{25}$ In contrast, a suggestive elevated risk of mortality in nulliparous women was observed in our analyses. The discrepancy in findings may be due to differences in the study populations across different periods in time. A recent analysis in US women found a small increase in all-cause mortality in nulliparous women. ${ }^{24}$ Two recent meta-analyses ${ }^{26} 27$ and a Japanese cohort study ${ }^{22}$ showed that nulliparous women have the highest risk of mortality, which is consistent with our findings. These studies, however, also found higher risks of allcause or CVD mortality for women with a large number of total births (6-7 births), suggesting a J-shaped relationship between mortality and parity. The authors concluded that this might largely arise from behavior-related factors associated with parenting or socioeconomic position (ie, higher parous women are more likely to have lower socioeconomic status). This was not seen in our study, possibly reflecting a different relationship between socioeconomic status and parity in rural Bangladesh. In the present study, women with more than five births were much less likely to have a formal education but more likely to own land. In addition, a few studies included in these meta-analyses did not adjust for age, and this might explain the inconsistency between 


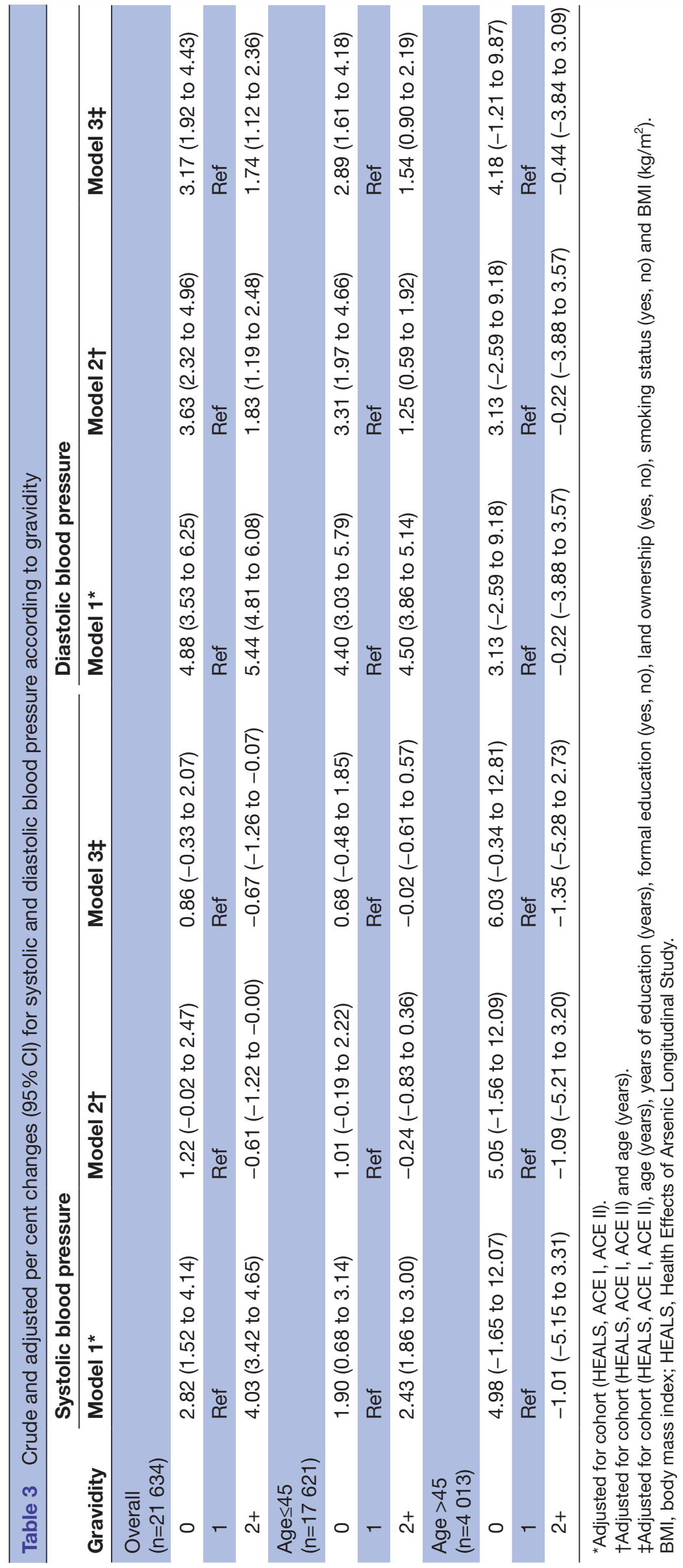




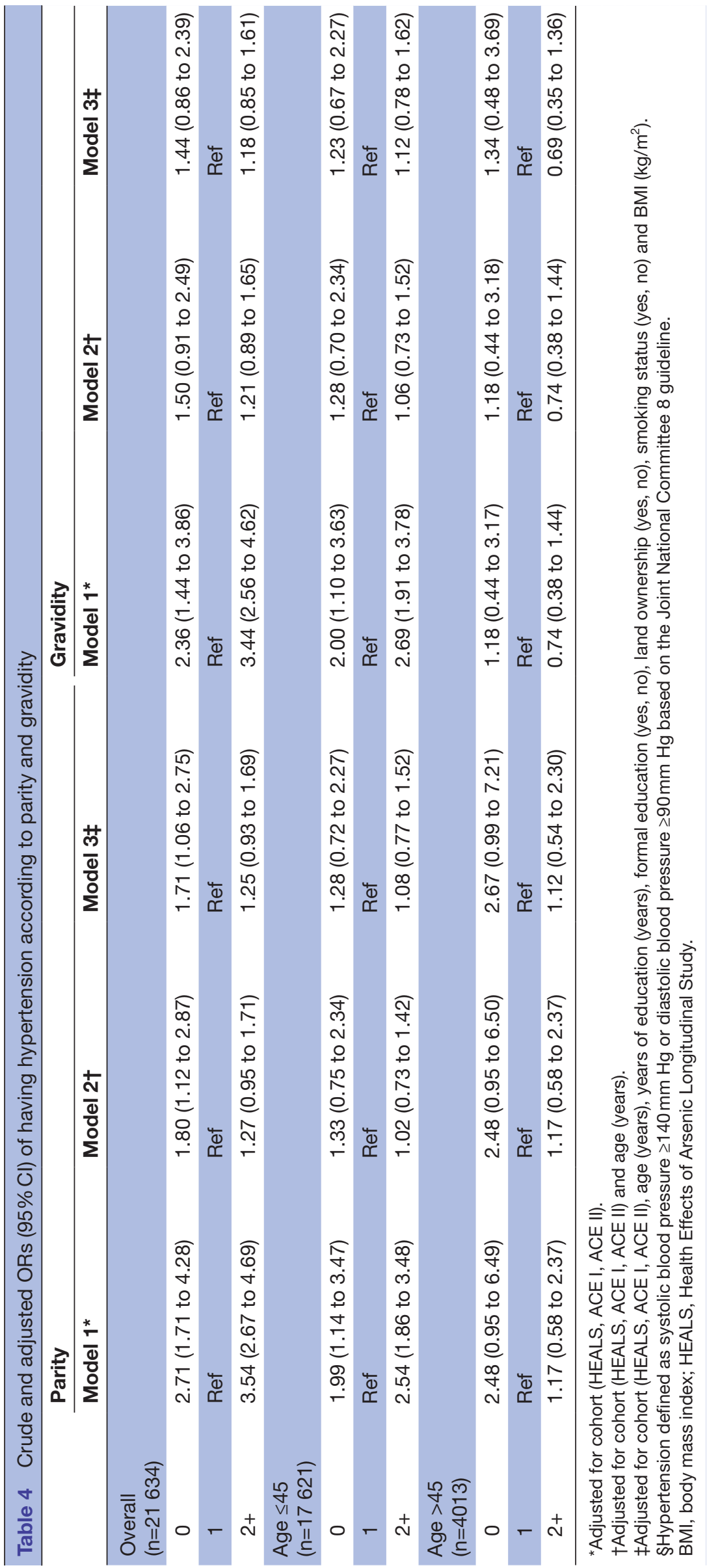


previous research and our findings. The large difference in the magnitude of the associations observed in the present study suggests that the effect is likely to differ by study populations, sample sizes and follow-up times.

A potential mechanism by which these effects occur is longer lifetime lactation duration. Lactation has been associated with short-term decreases in blood pressure as well as reduced risk of hypertension and CVD in middle age due to potentially lowered stress reactivity from the prolonged release of oxytocin. ${ }^{39} 40$ Further, accumulation of fat stores, insulin resistance and increases in circulating lipid levels are reversed by the mobilisation of those fat stores during lactation, with longer duration of lactation supporting more complete reversal of changes. ${ }^{41}$ In Bangladesh, the percentage of children breastfed in the second year of life is $92 \%,{ }^{42}$ and thus higher parity would correlate with much longer lifetime lactation duration in this population. While longer duration of breastfeeding may be explained by other maternal health behaviours in developed countries and therefore confound the relationship with cardiovascular health,$^{39}$ this is likely not the case in Bangladesh where long duration of breast feeding is the norm.

The present study has limitations that should be considered. First, since reproductive history was self-reported at the baseline visit, there is the possibility for misclassification of parity and gravidity, particularly among older women; however, we deem that self-reported parity is both reliable and valid. ${ }^{43}$ Additionally, menopausal status was not ascertained, and thus age was used as a proxy, which may have resulted in some misclassification. Even assuming some misclassification of menopausal status, the large changes in magnitude observed in the age-stratified analyses suggest that, on average, women over 45 years have a different relationship between reproductive history and hypertensive morbidity and mortality than younger women. Additionally, some unmeasured confounders, such as gestational weight gain (only a consideration for the findings related to parous women), ${ }^{44}$ underlying health issues (eg, polycystic ovary syndrome and uterine leiomyoma) and other socioeconomic status-related variables (eg, income), were not collected and remain unaccounted for in our statistical analyses. Lastly, understanding the effect of lactation on this relationship and independently could be explored to expand our understanding of maternal health benefits associated with lactation in low- and middle-income countries.

In conclusion, we have investigated the effects of pregnancy and childbirth on blood pressure and mortality and found that nulliparous and nulligravid women have the highest risk of hypertension. We also observed a modest increase in diastolic blood pressure for parity and gravidity higher than two. Future studies in populations with similar socioeconomic backgrounds and patterns of fertility are needed to confirm current findings.

Contributors MA, FP and HA designed the study and directed its implementation, including quality assurance and control. MSB, AA and TI helped supervise the field activities. Y-HS, MSB and MA designed the study's analytical strategy. Y-HS, MSB,
KHU and MA helped conduct the literature review and prepare the Methods and the Discussion sections of the text.

Funding This work was supported by the National Institutes of Health (grants P42 ES010349, R01 ES024423).

Competing interests None declared.

Patient consent for publication Not required.

Ethics approval The study protocol was approved by the institutional review boards of The University of Chicago, Columbia University, the University of Illinois at Chicago, and the Bangladesh Medical Research Council.

Provenance and peer review Not commissioned; externally peer reviewed.

Data availability statement Data are available on reasonable request and on approval from the project principal investigator.

Open access This is an open access article distributed in accordance with the Creative Commons Attribution Non Commercial (CC BY-NC 4.0) license, which permits others to distribute, remix, adapt, build upon this work non-commercially, and license their derivative works on different terms, provided the original work is properly cited, appropriate credit is given, any changes made indicated, and the use is non-commercial. See: http://creativecommons.org/licenses/by-nc/4.0/.

ORCID iD

Yu-Hsuan Shih http://orcid.org/0000-0002-9823-3771

\section{REFERENCES}

1 Rapsomaniki E, Timmis A, George J, et al. Blood pressure and incidence of twelve cardiovascular diseases: lifetime risks, healthy life-years lost, and age-specific associations in 1.25 million people. Lancet 2014;383:1899-911.

2 Angeli F, Reboldi G, Verdecchia P. Hypertension, inflammation and atrial fibrillation. J Hypertens 2014;32:480-3.

3 Organization WH. A global brief on hypertension: silent killer, global public health crisis. World Health Day, 2013.

4 Chowdhury MAB, Uddin MJ, Haque MR, et al. Hypertension among adults in Bangladesh: evidence from a national cross-sectional survey. BMC Cardiovasc Disord 2016;16:22.

5 Chobanian AV, Bakris GL, Black HR, et al. The seventh report of the joint National Committee on prevention, detection, evaluation, and treatment of high blood pressure: the JNC 7 report. JAMA 2003;289:2560-72.

6 Kelsey JL, Gammon MD, John EM. Reproductive factors and breast cancer. Epidemiol Rev 1993;15:36-47.

7 Benz C, Hollander C, Miller B. Endocrine-responsive pancreatic carcinoma: steroid binding and cytotoxicity studies in human tumor cell lines. Cancer Res 1986;46:2276-81.

8 Gunderson EP, Chiang V, Lewis CE, et al. Long-Term blood pressure changes measured from before to after pregnancy relative to nonparous women. Obstet Gynecol 2008;112:1294-302.

9 Lawlor DA, Emberson JR, Ebrahim S, et al. Is the association between parity and coronary heart disease due to biological effects of pregnancy or adverse lifestyle risk factors associated with childrearing? findings from the British women's heart and health study and the British regional heart study. Circulation 2003;107:1260-4.

10 Behrens I, Basit S, Melbye M, et al. Risk of post-pregnancy hypertension in women with a history of hypertensive disorders of pregnancy: nationwide cohort study. BMJ 2017;358:j3078.

11 Mosca L, Benjamin EJ, Berra K, et al. Effectiveness-based guidelines for the prevention of cardiovascular disease in women--2011 update: a guideline from the American Heart Association. J Am Coll Cardiol 2011;57:1404-23.

12 Jang M, Lee Y, Choi J, et al. Association between parity and blood pressure in Korean women: Korean National health and nutrition examination survey, 2010-2012. Korean J Fam Med 2015;36:341-8.

13 Wild RA. Polycystic ovary syndrome: a risk for coronary artery disease? Am J Obstet Gynecol 2002;186:35-43.

14 Aksoy Y, Sivri N, Karaoz B, et al. Carotid intima-media thickness: a new marker of patients with uterine leiomyoma. Eur J Obstet Gynecol Reprod Biol 2014;175:54-7.

15 Ness RB, Kramer RA, Flegal KM. Gravidity, blood pressure, and hypertension among white women in the second National health and nutrition examination survey. Epidemiology 1993;4:303-9.

16 Lee-Feldstein A, Harburg E, Hauenstein L. Parity and blood pressure among four race-stress groups of females in Detroit. Am J Epidemiol 1980;111:356-66. 
17 Khalid MEM. The effect of age, obesity and parity on blood pressure and hypertension in non-pregnant married women. J Family Community Med 2006;13:103-7.

18 Taylor JY, Chambers AN, Funnell B, et al. Effects of parity on blood pressure among African-American women. J Natl Black Nurses Assoc 2008;19:12-19.

19 Taylor JY, Sampson DA, Anderson CM, et al. Effects of parity on blood pressure among West African Dogon women. Ethn Dis 2012;22:360-6.

20 Dratva J, Schneider C, Schindler C, et al. Is there a differential impact of parity on blood pressure by age? J Hypertens 2014;32:2146-51.

21 Haug EB, Horn J, Markovitz AR, et al. The impact of parity on life course blood pressure trajectories: the HUNT study in Norway. Eur $J$ Epidemiol 2018;33:751-61.

22 Yasukawa S, Eguchi E, Ogino K, et al. as a Modifier of the ParityCardiovascular Mortality Association - The Japan Collaborative Cohort Study. Circulation Journal 2018;82:1302-8.

23 Kravdal Øystein, Tverdal A, Grundy E. The association between parity, CVD mortality and CVD risk factors among Norwegian women and men. Eur J Public Health 2020:ckz235.

24 Gaudet MM, Carter BD, Hildebrand JS, et al. Associations of parity and age at first pregnancy with overall and cause-specific mortality in the cancer prevention study II. Fertil Steril 2017;107:179-88.

25 Elajami TK, Giuseffi J, Avila MD, et al. Parity, coronary heart disease and mortality in the old order Amish. Atherosclerosis 2016;254:14-19.

26 Lv H, Wu H, Yin J, et al. Parity and cardiovascular disease mortality: a dose-response meta-analysis of cohort studies. Sci Rep 2015;5:13411.

27 Zeng Y, Ni Z-min, Liu S-yun, et al. Parity and all-cause mortality in women and men: a dose-response meta-analysis of cohort studies. Sci Rep 2016;6:19351.

28 Hurt LS, Ronsmans C, Campbell OMR, et al. Long-Term effects of reproductive history on all-cause mortality among adults in rural Bangladesh. Stud Fam Plann 2004;35:189-96.

29 Ahsan H, Chen Y, Parvez F, et al. Health effects of arsenic longitudinal study (heals): description of a multidisciplinary epidemiologic investigation. J Expo Sci Environ Epidemiol 2006;16:191-205.

30 O'Brien E, Waeber B, Parati G, et al. Blood pressure measuring devices: recommendations of the European Society of hypertension. BMJ 2001;322:531-6.

31 Tobin MD, Sheehan NA, Scurrah KJ, et al. Adjusting for treatment effects in studies of quantitative traits: antihypertensive therapy and systolic blood pressure. Stat Med 2005;24:2911-35.
32 Balakrishnan P, Beaty T, Young JH, et al. Methods to estimate underlying blood pressure: the Atherosclerosis risk in communities (ARIC) study. PLoS One 2017;12:e0179234.

33 James PA, Oparil S, Carter BL, et al. 2014 evidence-based guideline for the management of high blood pressure in adults: report from the panel members appointed to the eighth joint National Committee (JNC 8). JAMA 2014;311:507-20.

34 Organization WH. The ICD-10 classification of mental and behavioural disorders: clinical descriptions and diagnostic guidelines. Geneva, 1992.

35 Taddei S. Blood pressure through aging and menopause. Climacteric 2009;12 Suppl 1:36-40.

36 Zanchetti A, Facchetti R, Cesana GC, et al. Menopause-related blood pressure increase and its relationship to age and body mass index: the SIMONA epidemiological study. J Hypertens 2005;23:2269-76.

37 Shen Q, Lin D, Jiang X, et al. Blood pressure changes and hormonal contraceptives. Contraception 1994;50:131-41.

38 Wenger NK. Female-friendly focus: 2019 ACC/AHA guideline on the primary prevention of cardiovascular disease. Clin Cardiol 2019;42:706-9.

39 Stuebe A. Associations among lactation, maternal carbohydrate metabolism, and cardiovascular health. Clin Obstet Gynecol 2015;58:827-39.

40 Nguyen B, Jin K, Ding D. Breastfeeding and maternal cardiovascular risk factors and outcomes: a systematic review. PLoS One 2017;12:e0187923.

41 Stuebe AM, Rich-Edwards JW. The reset hypothesis: lactation and maternal metabolism. Am J Perinatol 2009;26:081-8.

42 Global UNICEF Global Databases. Infant and young child feeding: continued breastfeeding. United Nations Children's Fund, Division of Data Research and Policy, 2018.

43 Espeut D, Becker S. The validity of birth and pregnancy histories in rural Bangladesh. J Health Popul Nutr 2015;33:17.

44 LifeCycle Project-Maternal Obesity and Childhood Outcomes Study Group, Voerman E, Santos S, et al. Association of gestational weight gain with adverse maternal and infant outcomes. JAMA 2019;321:1702-15

45 Soria-Contreras DC, Rifas-Shiman SL, Aris IM, et al. Weight trajectories after delivery are associated with adiposity and cardiometabolic markers at 3 years postpartum among women in project VIVA. J Nutr 2020;150:1889-98. 